University of Wollongong

Research Online

Australian Institute for Innovative Materials -

Papers

Australian Institute for Innovative Materials

$1-1-2019$

\title{
Ordered platinum-bismuth intermetallic clusters with Pt-skin for a highly efficient electrochemical ethanol oxidation reaction
}

Binwei Zhang

University of Wollongong, bz370@uowmail.edu.au

Weihong Lai

University of Wollongong,w1478@uowmail.edu.au

Tian Sheng

Anhui University

Xi-Ming Qu

Xiamen University

Yunxiao Wang

University of Wollongong, yunxiao@uow.edu.au

See next page for additional authors

Follow this and additional works at: https://ro.uow.edu.au/aiimpapers

Part of the Engineering Commons, and the Physical Sciences and Mathematics Commons

Research Online is the open access institutional repository for the University of Wollongong. For further information contact the UOW Library: research-pubs@uow.edu.au 


\title{
Ordered platinum-bismuth intermetallic clusters with Pt-skin for a highly efficient electrochemical ethanol oxidation reaction
}

\author{
Abstract \\ The ethanol oxidation reaction is extensively explored, but electrocatalysts that could achieve a complete \\ oxidation pathway to $\mathrm{CO} 2$ / $\mathrm{CO} 32$ - are much less reported. Here, we synthesize a monatomic Pt layer (Pt- \\ skin) on ordered intermetallic PtBi clusters (PtBi@Pt) supported on graphene via a single atom self- \\ assembling (SAS) method to form a superior catalyst. The PtBi@Pt with an ultrafine size $(\sim 2 \mathrm{~nm})$ delivers

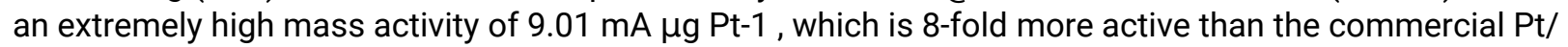 \\ C; significantly, in situ Fourier transform infrared spectroscopy indicates that ethanol is completely \\ oxidized to CO 32- on the PtBi@Pt, accompanied by 12 electron transfer, as is further demonstrated by the \\ density functional theory results.

\section{Disciplines} \\ Engineering | Physical Sciences and Mathematics

\section{Publication Details} \\ Zhang, B., Lai, W., Sheng, T., Qu, X., Wang, Y., Ren, L., Zhang, L., Du, Y., Jiang, Y., Sun, S. \& Dou, S. (2019). \\ Ordered platinum-bismuth intermetallic clusters with Pt-skin for a highly efficient electrochemical ethanol \\ oxidation reaction. Journal of Materials Chemistry A, 7 (10), 5214-5220.

\section{Authors} \\ Binwei Zhang, Weihong Lai, Tian Sheng, Xi-Ming Qu, Yunxiao Wang, Long Ren, Lei Zhang, Yi Du, Yan-Xia \\ Jiang, Shi-Gang Sun, and Shi Xue Dou
}




\section{Journal of Materials Chemistry A}

\section{COMMUNICATION}

\section{Ordered Platinum-Bismuth Intermetallic Clusters with Pt-skin for High Efficient Electrochemical Ethanol Oxidation Reaction}

Received 00th January 20xx Accepted 00th January 20xx

DOI: $10.1039 / \times 0 \times x 00000 x$

\author{
Bin-Wei Zhang, ${ }^{a}$ Tian Sheng, ${ }^{b}$ Xi-Ming Qu, ${ }^{c}$ Yun-Xiao Wang, ${ }^{\text {a a }}$ Long Ren, ${ }^{a}$ Lei Zhang, ${ }^{a}$ Yi Du, ${ }^{a}$ Yan-Xia
} Jiang, ${ }^{c}$ Shi-Gang Sun, ${ }^{*}$ and Shi-Xue Dou ${ }^{a}$

www.rsc.org/

Even though the ethanol oxidation reaction is extensively explored, electrocatalysts that could achieve complete oxidation pathway to $\mathrm{CO}_{2}$ are very rare. Here, we synthesize the monatomic Pt layer (Pt-skin) on ordered intermetallic PtBi clusters (PtBi@Pt) supported on graphene via a single atoms self-assembling (SAS) method to form a superior catalyst. The PtBi@Pt with ultrafine size ( $2 \mathrm{~nm}$ ) delivers an extremely high mass activity of $9.01 \mathrm{~mA}$ $\mu \mathrm{g}_{\mathrm{Pt}^{-1}}$, which is 8-fold more active than commercial $\mathrm{Pt} / \mathrm{C}$; significantly, in-situ Fourier transform infrared spectroscopy indicates that ethanol is completely oxidized to $\mathrm{CO}_{3}{ }^{2-}$ on the PtBi@Pt, accompanied by 12 electron transfer, as is further demonstrated by the density functional theory results.

Fuel cells have been gaining increasing attention because they are efficient and green power sources suitable for portable electronic devices and automotive applications..$^{1-4}$ In comparison with $\mathrm{H}_{2}$ fuel cells, direct ethanol fuel cells (DEFCs), as one of the most promising renewable energy applications, have many obvious advantages, such as low toxicity, high energy density, and inexhaustible availability from biomass..$^{5-6}$ It is widely accepted that the ethanol oxidation reaction (EOR) involves two parallel oxidation pathways: complete oxidation and partial oxidation. The complete electro-oxidation of ethanol with the transfer of 12 electrons is accompanied by breaking the $\mathrm{C}-\mathrm{C}$ bond, leading to the formation of $\mathrm{CO}_{2}$ (acid media) or $\mathrm{CO}_{3}{ }^{2-}$ (alkaline solutions), which is the $\mathrm{C} 1$ pathway. For incomplete oxidation ( $\mathrm{C} 2$ pathway), the final oxidation product of ethanol is acetate, with the reaction involving the transfer of $4 \mathrm{e}^{-}$. Despite $\mathrm{C} 1$ pathway possessing higher electroefficiency, most EOR electrocatalysts prefer the C2 pathway, which incompletely utilizes ethanol to form acetate as the final

a. Institute for Superconducting and Electronic Materials, Australian Institute of Innovative Materials, University of Wollongong, Innovation Campus, Squires Way, North Wollongong, New South Wales 2500, Australia.

b. College of Chemistry and Materials Science, Anhui Normal University, Wuhu, 241000, P. R. China.

State key laboratory of physical chemistry of solid surfaces, Department of Chemistry, College of Chemistry and Chemical Engineering, Xiamen University, Xiamen 361005, China.

Electronic Supplementary Information (ESI) available: See DOI: $10.1039 /$ x0xx00000x oxidation product; ${ }^{7-8}$ the proportion of Pt-based EOR electrocatalysts favoring the $\mathrm{C} 1$ pathway at room temperature is only $1 \%$, according to previous reports, because splitting the C-C bond is kinetically hindered. ${ }^{9-11}$ To date, the most effective strategy to enhance the ability to split the $\mathrm{C}-\mathrm{C}$ bond and improve the selectivity involves modifying the electronic structure of Pt based electrocatalysts by introducing Rh; ${ }^{12-13}$ it is widely believed that synergistic reactions exist in such multicomponent systems, which could weaken the bonding of intermediates and offer additional adsorbed hydroxyl groups, $\mathrm{OH}_{\mathrm{ads}}$, to aid in the further oxidation of carbonaceous intermediates. ${ }^{14}$ Nevertheless, the production of $\mathrm{Rh}$ is extremely rare, even lower than that of Pt. Rational design of electrocatalysts, which can reduce cost and simultaneously allow them to work via the C1 pathway, is a very powerful objective for the EOR.

It is a remarkable fact that those electrocatalytic reactions only take place on the surface of the catalysts; ${ }^{15}$ thus, intensities studies have been carried out to tuning the surface composition of bimetallic electrocatalysts. ${ }^{16-19}$ The most successful bimetallic electrocatalysts for controlling surface composition is the Pt-skin structure, ${ }^{20-22}$ which boosting the activity of electrocatalysts. Despite the fact that Pt-skin of $\mathrm{Pt}_{3} \mathrm{Co}$ could enhance activity of EOR, it still goes through the incomplete oxidation pathway. Nevertheless, the prosperity of Pt-skin surface is dependent on the inner atoms, which cause the compressive or tensile strain of the Pt-surface; these strain effect will open up new idea to design electrocatalysts. A good example is that the PtPb/Pt core/shell nanoplates, with large biaxial tensile strain, exhibit amazing activity, which used to be believed that could not effectivity improve the oxygen reduction reaction. ${ }^{23}$ Besides, the structure of catalysis also affect their electrochemical performance; thus great attention on the morphology of electrocatalysis such as nanowires, ${ }^{24,25}$ nanoporous, ${ }^{26}, 27$ and nanoclusters ${ }^{28-30}$ materials, are paid. Based on this view, tuning the strain effect of the Pt-skin via exploiting favorable inner atoms and controlling the structure of electrocatalysis may achieve electro-oxididation ethanol via C1 pathway without a loss of catalytic performance. 
Herein, by introducing relatively cheap element $\mathrm{Bi}$ in the core, we report a superior catalyst with Pt-skin on order PtBi intermetallic (PtBi@Pt) supported on graphene matrix, which is fabricated from single-atom $\mathrm{Pt}$ mixed with $\mathrm{PtBi}$ catalyst (PtBi/SA Pt) via a single-atom self-assembling (SAS) method. The electrochemical performance towards the EOR of PtBi@Pt was first studied. It delivers a peak current density of $9.01 \mathrm{~mA}$ $\mu_{\mathrm{pt}}{ }^{-1}$ with much higher activity than PtBi/SA Pt and Pt/C even after stability testing, which significantly outperforms other reported catalysts for the EOR under alkaline conditions. Moreover, in-situ Fourier transform infrared spectroscopy (FTIR) demonstrates that the final product of the $\mathrm{EOR}$ is $\mathrm{CO}_{3}{ }^{2-}$, confirming the selectivity of the C1 pathway.

The core-skin PtBi@Pt was gradually synthesized by controlling thermal treatment temperatures without using any surfactant or organometallic precursors. Firstly, an intermediate, $\mathrm{PtBi} / \mathrm{SA}$ $\mathrm{Pt}$, is prepared by controlled thermal treatment method at 600 oC for $12 \mathrm{~h}$ (Supported Information). By increasing the thermal treatment time to $24 \mathrm{~h}$, as illustrated in Figure 1a, these single Pt atoms stabilized by graphene will migrate to the surface of the ordered $\mathrm{PtBi}$ intermetallic, and then self-assemble to form Pt-skin on the ordered PtBi intermetallic clusters. The formation of single $\mathrm{Pt}$ atoms in $\mathrm{PtBi} / \mathrm{SA} \mathrm{Pt}$ is mostly ascribed to that the functional groups of graphene could stabilize the single $\mathrm{Pt}$ atoms; ${ }^{31}$ and part of the $\mathrm{Pt}$ will be reduced together with $\mathrm{Bi}$ by $\mathrm{H}_{2}$ at $600 \stackrel{\circ}{\mathrm{C}}$ to form an ordered PtBi intermetallic. Figure $1 \mathrm{~b}$ and Figure $\mathrm{S} 1$ show atomic resolution high-angle annular dark field (HAADF) scanning transmission electron microscope (STEM) images of PtBi/SA Pt, which demonstrate that isolated $\mathrm{Pt}$ single atoms are uniformly distributed at high density throughout the graphene, and PtBi clusters are also detected, with dimensions of $\sim 1.3 \pm 0.5 \mathrm{~nm}$. There are so many single Pt atoms in the Figure $1 \mathrm{~b}$ and S1, so we just circle some of them, demonstrating the presence of SA Pt in PtBi/SA Pt. In particular, the Bi columns could show higher intensity than the Pt columns, due to the fact that the atomic number $Z$ of $B i$ is 83 , which is higher than that of $\mathrm{Pt}(Z=78) .{ }^{32}$ By comparing the brightness variation of $\mathrm{Pt}$ and $\mathrm{Bi}$ intensities in the HAADF images, we concluded that these single atoms were Pt. There are some Pt clusters $(<0.5 \mathrm{~nm})$, containing 2-3 Pt atoms, in $\mathrm{PtBi} / \mathrm{SA} \mathrm{Pt}$; the reason why PtBi/SA Pt exists in clusters is that it is difficult to stabilize pure metal atoms in graphene due to their mobility and instability; ${ }^{31}$ and at such high Pt loading level ( 8.24\%), it is easy to form clusters.33 The image of PtBi@Pt (Figure 1c) demonstrates that most of these clusters are well dispersed on the graphene, accompanied by the SA Pt selfassembling on $\mathrm{PtBi}$ intermetallic. To determine the monatomic nature of the Pt layer on PtBi@Pt, we examined two sites by intensity analysis, which are shown in Figure 1e. Both sites have 1-2 atomic layer of $\mathrm{Pt}$; $\mathrm{Pt}$ and $\mathrm{Bi}$ appear to be distributed alternately, as shown by the alternating brightness and darkness in Figure 1d, indicating that these PtBi intermetallic clusters are ordered. Furthermore, the $d$-spacings of $2.15 \AA$ and $2.22 \AA$ correspond to the (110) and (012) planes of PtBi intermetallic, respectively, indicating that the clusters are viewed along the [001] zone axis. ${ }^{34}$ This inner PtBi intermetallic certain will have a tensile strain on the Pt-skin surface. The mean size of PtBi@Pt is evaluated to be $\sim 2.0 \pm 0.7 \mathrm{~nm}$, as analyzed from 200 clusters (Figure S2, Supporting Information), which indicates that after long time thermal treatment, SA Pt and $\mathrm{Pt}$ cluster could self-assemble on the surface of PtBi cluster, and formation of bigger clusters. We also examine many areas of PtBi@Pt, and they don't present single Pt atoms, which suggest that most of $\mathrm{PtBi}$ particles were converted to PtBi@Pt. The X-ray diffraction (XRD) results in Figure 1f demonstrate that the PtBi phase in PtBi/SA Pt and PtBi@Pt is in good agreement with the ordered $P$ tBi intermetallic phase. ${ }^{35}$ The broad peak at $\sim 26$ o is assigned to the graphene.

$\mathrm{X}$-ray photoelectron spectroscopy (XPS) is applied to investigate the chemical states of $\mathrm{Pt}$ and $\mathrm{Bi}$, as shown in Figure 2. The $P t 4 f_{7 / 2}$ spectrum can be deconvoluted into pure $\mathrm{Pt}\left(\mathrm{Pt}^{0}\right)$ and $\mathrm{Pt}^{2+}$; the binding energy $(\mathrm{BE})$ of $\mathrm{Pt}^{0}$ in $\mathrm{PtBi} / \mathrm{SA} \mathrm{Pt}$ and $\mathrm{PtBi} @ \mathrm{Pt}$ are 71.60 and $71.35 \mathrm{eV}$, respectively. Interestingly, the $\mathrm{BE}$ of $\mathrm{Pt}^{0}$ in $\mathrm{PtBi} @ \mathrm{Pt}$ is near to that in pure $\mathrm{Pt}(71.2 \mathrm{eV})$, which indicates that the surface states of PtBi@Pt are close to those of metallic Pt. It also implies that the electronic structure of the Pt-skin surface is modified by the inner ordered PtBi intermetallic, which results in tensile strain of Pt-skin surface. In contrast, the $\mathrm{BE}$ of $\mathrm{Pt}^{0}$ in $\mathrm{PtBi} / \mathrm{SA} \mathrm{Pt}$ is the highest; the difference in the values indicates that $\mathrm{Pt}$ in the ordered $\mathrm{PtBi}$ intermetallic has a strong interaction with $\mathrm{Bi}$ and that single $\mathrm{Pt}$ atoms are oxidized as $\mathrm{Pt}^{2+}$ (i.e. PtO). ${ }^{36}$ The XPS reflect the overall state of materials, thus demonstrating that mainly single Pt atoms self-assemble to form Pt-skin on PtBi@Pt. The Bi XPS spectrum in PtBi/SA Pt and PtBi@Pt is similar (Figure 2b) Both of them only have $\mathrm{Bi}^{3+}$, and the $\mathrm{BE}$ is $159.0 \mathrm{eV}$; this also demonstrates that there is a strong interaction between $\mathrm{Pt}$ and $\mathrm{Bi}$ in the ordered $\mathrm{PtBi}$ intermetallic. ${ }^{37}$

Cyclic voltammograms (CVs) of Pt/C, PtBi/SA Pt and PtBi@Pt in $1 \mathrm{M} \mathrm{KOH}$ solution are shown in Figure $\mathrm{S6}$, where neither of the $\mathrm{PtBi}$ catalysts show any apparent hydrogen adsorption or desorption compared with $\mathrm{Pt} / \mathrm{C}$. This result indicates the presence of $\mathrm{Bi}$ in the core would modify the electron state of surface of $\mathrm{Pt}$ and block the sites for adsorbed monatomic hydrogen, $\mathrm{H}_{\mathrm{ads}}$. The similar characteristic also been observed in the Pt-skin of $\mathrm{Pt}_{3} \mathrm{Co}$ and $\mathrm{Pt}_{3} \mathrm{Ni}, 7,15$ which also suggested the presence of Pt-skin on the PtBi@Pt. Thus, the CV properties of both PtBi/SA Pt and PtBi@Pt could be assigned to the formation of ordered PtBi intermetallic. ${ }^{35,} 15$ The electrocatalytic characteristics of the EOR for these three catalysts were investigated in a basic medium $\left(1 \mathrm{M} \mathrm{CH}_{3} \mathrm{CH}_{2} \mathrm{OH}\right.$ and $1 \mathrm{M} \mathrm{KOH}$ ), as shown in Figure 3a. All of them exhibited one forward scan peak, corresponding to the oxidation of $\mathrm{CH}_{3} \mathrm{CH}_{2} \mathrm{OH}$ to intermediate products ${ }^{38,39}$ and one reverse scan peak, typically assigned to the further oxidation of intermediate products. ${ }^{38,} 39$ Significantly, PtBi@Pt shows the highest peak current in the forward anodic scan of $9.01 \mathrm{~mA}$ $\mu \mathrm{gpt}^{-1}$ at $-0.114 \mathrm{~V}$, when compared with PtBi/SA Pt (4.69 mA $\mu \mathrm{g}^{-1}$ at $\left.-0.067 \mathrm{~V}\right), \mathrm{Pt} / \mathrm{C}\left(1.09 \mathrm{~mA} \mu \mathrm{g}_{\mathrm{pt}}{ }^{-1}\right.$ at -0.119$)$, and results in the recent literatures (Table S1). It is widely acknowledged that the ratio of the forward peak current $\left(l_{f}\right)$ to the reverse peak current $\left(I_{r}\right)$ reflects the toleration of electrocatalyst against poisoning. ${ }^{40}$ The value of $I_{f} / I_{r}$ for PtBi@Pt is 1.59, which is higher than those of PtBi/SA Pt (1.06) and Pt/C (1.05), 
indicating that the PtBi@Pt electrocatalyst has the best tolerance to intermediate accumulation. The current-time curves at $-0.3 \mathrm{~V}(\mathrm{Hg} / \mathrm{HgO})$ on these three catalysts at room temperature are shown in Figure 3b. After $1800 \mathrm{~s}$, the activity of PtBi@Pt is still higher than those of PtBi/SA Pt and Pt/C, demonstrating that $\mathrm{PtBi} @ \mathrm{Pt}$ possesses better operation stability. To further investigate the electrochemical durability of the PtBi@Pt and PtBi/SA Pt, they were evaluated at the potential between -0.4 and $0.1 \mathrm{~V}$ versus $\mathrm{Hg} / \mathrm{HgO} 5,000$ cycles in $1 \mathrm{M} \mathrm{KOH}$ solution, as shown in Figure S10. After 5,000 sweeping cycles, PtBi@Pt also maintains a high mass activity of $7.08 \mathrm{~mA} \mu \mathrm{gt}^{-1}$; however, under the same condition, the $\mathrm{PtBi} / \mathrm{SA}$ Pt only remains $2.10 \mathrm{~mA} \mu \mathrm{g}_{\mathrm{Pt}}^{-1}$ and almost $50 \%$ loss of mass activity. This high activity of PtBi@Pt could be attributed to the tensile strain of Pt-skin surface from the inner ordered $\mathrm{PtBi}$ inermetallic ${ }^{41}$, which may promote the ethanol dehydrogenation; meanwhile, the better stability of PtBi@Pt may also originate from their special structure, in which the Ptskin structure could prevent the loss of the interior $\mathrm{Bi}$ during CVs and durability test.

Unlike Pt-skin surface of $\mathrm{Pt}_{3} \mathrm{Co} @ \mathrm{Pt}$ only enhancing the activity via C2 pathway, ${ }^{7}$ the Pt-skin surface of PtBi@Pt may both improve the acitivity and selectivity of EOR. To evaluate the selectivity towards ethanol oxidation, in-situ FTIR was applied to identify the intermediate and final products of these three samples, as shown in Figure 3c-e. The signature peak at 1550 $\mathrm{cm}^{-1}$, found in all three samples, is attributed to the asymmetric stretching vibrations of the carboxyl group in $\mathrm{CH}_{3} \mathrm{COOH}$, which is usually applied to the analysis of incomplete oxidation of $\mathrm{CH}_{3} \mathrm{CH}_{2} \mathrm{OH}$. $^{7}{ }^{42}$ Notably, in none of these three samples can the signature peak of $\mathrm{CO}_{2}\left(2345 \mathrm{~cm}^{-1}\right)$ be detected, suggesting that the $\mathrm{KOH}$ in solution reacts with $\mathrm{CO}_{2}$, leading to the formation of $\mathrm{CO}_{3}{ }^{2-}$. Therefore, the symmetric stretching band of $\mathrm{COO}$ at $1415 \mathrm{~cm}^{-1}$ is coming from the superposition of bands from $\mathrm{CO}_{3}{ }^{2-}$ and $\mathrm{CH}_{3} \mathrm{COO}$, which represents the overall electro-oxidation of $\mathrm{CH}_{3} \mathrm{CH}_{2} \mathrm{OH} .{ }^{35}$ To investigate the capability for $\mathrm{C}-\mathrm{C}$ bond breaking in $\mathrm{CH}_{3} \mathrm{CH}_{2} \mathrm{OH}$, we compared the ratio of integrated intensities associated with total electro-oxidation $\left(1415 \mathrm{~cm}^{-1}\right)$ and incomplete electro-oxidation $\left(1550 \mathrm{~cm}^{-1}\right)$ at various working potentials, as shown in Figure 3f. The results show that the value in PtBi@Pt for the C1 pathway is above 90\%, demonstrating that the compressive strain of the Pt-skin surface influenced by inner $\mathrm{PtBi}$ intermetallic could enhance the selectivity towards the C1 pathway. Remarkably, the values for the $C 1$ pathway in $\mathrm{PtBi} / \mathrm{SA} \mathrm{Pt}$ and $\mathrm{Pt} / \mathrm{C}$ are reduced to $30 \%$ and $50 \%$, respectively, indicating that the activity of both of them towards ethanol electro-oxidation is primarily via the $\mathrm{C} 2$ pathway, especially at high potential $(>-0.7 \mathrm{~V}$ ). This result suggests that, although single $\mathrm{Pt}$ atoms and ordered $\mathrm{PtBi}$ intermetallic have high reactivity, they show very poor EOR selectivity; when single $\mathrm{Pt}$ atoms are segregated on the surface of PtBi intermetallic, PtBi@Pt not only has high activity, but also could completely oxidize ethanol to $\mathrm{CO}_{3}{ }^{2-}$.

According to the theoretical model proposed in the literature, $^{43}$ the $\mathrm{C} 1$ product selectivity can be estimated quantitatively by comparing the barrier difference between $\alpha$ - dehydrogenation and $\beta$-dehydrogenation, i.e., $\Delta E_{\mathrm{a}}=E_{\mathrm{a}, \alpha-\mathrm{CH}}-$ $E_{\mathrm{a}, \mathrm{B}-\mathrm{CH}}$, where $E_{\mathrm{a}}$ is the activation energy. As shown in Figure 4, on the PtBi(0001) surface with a single Pt site, the $\alpha-\mathrm{C}-\mathrm{H}$ bond breaks to form $\mathrm{CH}_{3} \mathrm{COH}^{*}\left(E_{\mathrm{a}, \alpha-\mathrm{CH}}=0.83 \mathrm{eV}\right)$, which is more kinetically favored than the $\beta-\mathrm{C}-\mathrm{H}$ bond $\left(E_{\mathrm{a}, \beta-\mathrm{CH}}=0.93 \mathrm{eV}\right)$, formation of $\mathrm{CH}_{2} \mathrm{CHOH}^{*}$; as a result, the $\Delta E_{\mathrm{a}}$ of the $\mathrm{PtBi}(0001)$ surface with a single Pt site is $-0.1 \mathrm{eV}$, indicating that $\mathrm{CH}_{3} \mathrm{CO}^{*}$ would be the predominate product on the surface derived from ethanol decomposition, which could then be oxidized to acetate. When more $\mathrm{Pt}$ atoms are adsorbed at the adjacent position near the single Pt site, impressively, the new surface is found to be very reactive towards the $\beta-\mathrm{C}-\mathrm{H}$ bond breaking process; the calculated barrier for $\mathrm{CH}_{2} \mathrm{CHOH}^{*}$ formation is 0.79 $\mathrm{eV}$, which is lower than $0.93 \mathrm{eV}$ for $\mathrm{CH}_{3} \mathrm{COH}^{*}$ formation. Therefore, the $\Delta E_{\mathrm{a}}$ of the $\mathrm{Pt}-\mathrm{PtBi}(0001)$ is $0.14 \mathrm{eV}$, indicating that it mainly product is $\mathrm{CH}_{2} \mathrm{CHOH}^{*}$, which will form $\mathrm{CH}_{2} \mathrm{CO}^{*}$; this result also confirms that the tensile strain of Pt-skin surface from the inner $\mathrm{PtBi}$ inermetallic would help the dehydrogenation of ethanol. Significantly, the $\mathrm{CH}_{2} \mathrm{CO}$ * acts as a further precursor for $\mathrm{C}-\mathrm{C}$ bond splitting, demonstrating that it could via C1 pathway. This result is corresponding to the in situ FTIR results, demonstrating that ethanol will be oxidized to $\mathrm{CO}_{2}$ on PtBi@Pt.

\section{Conclusions}

In summary, the core-skin PtBi@Pt was successfully prepared by the single Pt atoms self-assembling on the surface of PtBi intermetallic using the SAS method. Rather than utilizing compressive strain to enhance the EOR activity, the tensile strain of Pt-skin surface of PtBi@Pt was realized to achieve a very high mass activity of $9.01 \mathrm{~mA} \mu_{\mathrm{Pt}^{-1}}{ }^{-1}$, which is 8.26 times higher than that of Pt/C towards the EOR. Remarkably, the insitu FTIR spectra and DFT results demonstrate that PtBi@Pt has better selectivity towards the EOR, which mainly proceeds via the $\mathrm{C} 1$ pathway, while $\mathrm{PtBi} / \mathrm{SA} \mathrm{Pt}$ and $\mathrm{Pt} / \mathrm{C}$ mainly go through the $C 2$ pathway. Such Pt-skin surface synthesized from a general approach is promotional to enhance the catalytic activity and selectivity toward these multimetal active sites chemical reactions.

\section{Conflicts of interest}

There are no conflicts to declare.

\section{ACKNOWLEDGMENT}

This research was supported by the Australian Research Council (ARC) (DE170100928 and DP170101467), The Natural Science Foundation of China (21621091), the Commonwealth of Australia through the Automotive Australia 2020 Cooperative Research Centre (AutoCRC), and the BaosteelAustralia Joint Research and Development Center (Baosteel Grant no. BA14006). The authors acknowledge the use of the facilities at the UOW Electron Microscopy Centre funded by 
ARC grants (LE0882813 and LE0237478) and Dr. Tania Silver for her critical reading.

\section{Notes and references}

1 M. Liu, R. Zhang, W. Chen, Chem. Rev. 2014, 114, 5117.

2 Y. G. Guo, J. S. Hu, L. J. Wan, Adv. Mater. 2008, 20, 2878.

3 Z. Wu, Y. Lv, Y. Xia, P. A. Webley, D. Y. Zhao, J. Am. Chem. Soc. 2012, 134, 2236

4 C. Guo, Y. Zheng, J. Ran, F. Xie, M. Jaroniec, S. Z. Qiao, Angew. Chem. Int. Ed. 2017, 56, 8359.

5 W. Du, G. Yang, E. Wong, N. A. Deskins, A. I. Frenkel, D. Su, X. Teng, J. Am. Chem. Soc. 2014, 136, 10862.

6 N. Erini, R. Loukrakpam, V. Petkov, E. A. Baranova, R. Yang, D. Teschner, Y. Huang, S. R. Brankovic, P. Strasser, ACS Catal. 2014, 4, 1859.

7 B. W. Zhang, T. Sheng, Y. X. Wang, X. M. Qu, J. M. Zhang, Z. C. Zhang, H. G. Liao, F. C. Zhu, S. X. Dou, Y. X. Jiang, S. G. Sun, ACS Catal. 2017, 7, 892

8 A. Ferre-Vilaplana, C. Buso-Rogero, J. M. Feliu, E. Herrero, J. Phys. Chem. C 2016, 120, 11590.

9 Y. Wang, S. Zou, W. B. Cai, Catalysts 2015, 5, 1507.

10 L. Jiang, L. Colmenares, Z. Jusys, G. Q. Sun, R. J. Behm, Electrochim. Acta 2007, 53, 377.

11 W. Huang, X. Y. Ma, H. Wang, R. Feng, J. Zhou, P. N. Duchesne, P. Zhang, F. Chen, N. Han, F. Zhao, J. Zhou, W. B. Cai, Y. Li, Adv. Mater. 2017, 29, 1703057.

12 A. Kowal, M. Li, M. Shao, K. Sasaki, M. B. Vukmirovic, J. Zhang, N. S. Marinkovic, P. Liu, A. I. Frenkel, R. R. Adzic, Nat. Mater. 2009, 8, 325

13 T. Sheng, Y. F. Xu, Y. X. Jiang, L. Huang, N. Tian, Z. Y. Zhou, I. Broadwell, S. G. Sun, Acc. Chem. Res. 2016, 49, 2569.

14 C. Bianchini, P. K. Shen, Chem. Rev. 2009, 109, 4183.

15 B. W. Zhang, H. L. Yang, Y. X. Wang, S. X. Dou, H. K. Liu, Adv. Energy Mater. 2018, 0, 1703597.

16 A. L. Strickler, A. Jackson, T. F. Jaramillo, ACS Energy Letters 2017, 2 (1), 244.

17 P. Wang, K. Jiang, G. Wang, J. Yao, X. Huang, Angew. Chem. Int. Ed. 2016, 55 (41), 12859.

18 Z. Niu, N. Becknell, Y. Yu, D. Kim, C. Chen, N. Kornienko, G. A. Somorjai, P. Yang, Nat. Mater. 2016, 15, 1188.

19 A. Oh, H. Baik, D. S. Choi, J. Y. Cheon, B. Kim, H. Kim, S. J. Kwon, S. H. Joo, Y. Jung, K. Lee, ACS Nano 2015, 9 (3), 2856.

20 V. R. Stamenkovic, B. Fowler, B. S. Mun, G. F. Wang, P. N. Ross, C. A. Lucas, N. M. Markovic, Science 2007, 315 (5811), 493.

21 V. R. Stamenkovic, B. S. Mun, M. Arenz, K. J. J. Mayrhofer, C. A. Lucas, G. Wang, P. N. Ross, N. M. Markovic, Na. Mater. 2007, 6 (3), 241.

22 C. Chen, Y. J. Kang, Z. Y. Huo, Z. W. Zhu, W. Y. Huang, H. L. Xin, J. D. Snyder, D. G. Li, J. A. Herron, M. Mavrikakis, M. F. Chi, K. L. More, Y. D. Li, N. M. Markovic, G. A. Somorjai, P. D. Yang, V. R. Stamenkovic, Science 2014, 343 (6177), 1339.

23 L. Bu, N. Zhang, S. Guo, X. Zhang, J. Li, J. Yao, T. Wu, G. Lu, J. Y. Ma, D. Su, X. Huang, Science 2016, 354 (6318), 1410.

24 C. Young, J. Wang, J. Kim, Y. Sugahara, J. Henzie, Y. Yamauchi, Chemistry of Materials 2018, 30, 3379.

25 M. Li, Z. Zhao, T. Cheng, A. Fortunelli, C.-Y. Chen, R. Yu, Q. Zhang, L. Gu, B. V. Merinov, Z. Lin, E. Zhu, T. Yu, Q. Jia, J. Guo, L. Zhang, W. A. Goddard, Y. Huang, X. Duan, Science 2016 $354,1414$.

26 C. Li, M. Iqbal, J. Lin, X. Luo, B. Jiang, V. Malgras, K. C. W. Wu, J. Kim, Y. Yamauchi, Accounts of chemical research 2018, 51, 1764.

27 C. Li, B. Jiang, Z. Wang, Y. Li, M. S. A. Hossain, J. H. Kim, T. Takei, J. Henzie, Ö. Dag, Y. Bando, Y. Yamauchi, Angewandte Chemie 2016, 128, 12938.
28 E. C. Tyo, S. Vajda, Nat Nano 2015, 10, 577

29 S. Yao, X. Zhang, W. Zhou, R. Gao, W. Xu, Y. Ye, L. Lin, X. Wen, P. Liu, B. Chen, E. Crumlin, J. Guo, Z. Zuo, W. Li, J. Xie, L. Lu, C. J. Kiely, L. Gu, C. Shi, J. A. Rodriguez, D. Ma, Science 2017, 357, 389.

30 Z. L. Wang, K. Sun, J. Henzie, X. Hao, C. Li, T. Takei, Y.-M. Kang, Y. Yamauchi, Angewandte Chemie International Edition 2018, 57, 5848

31 D. Deng, X. Chen, L. Yu, X. Wu, Q. Liu, Y. Liu, H. Yang, H. Tian, Y. Hu, P. Du, R. Si, J. Wang, X. Cui, H. Li, J. Xiao, T. Xu, J. Deng, F. Yang, P. N. Duchesne, P. Zhang, J. Zhou, L. Sun, J. Li, X. Pan, X. Bao, Sci. Adv. 2015, 1 (11).

32 W. Liu, L. Zhang, X. Liu, X. Liu, X. Yang, S. Miao, W. Wang, A. Wang, T. Zhang, J. Am. Chem. Soc. 2017, 139, 10790.

33 H. Wei, X. Liu, A. Wang, L. Zhang, B. Qiao, X. Yang, Y. Huang, S. Miao, J. Liu, T. Zhang, Nat. Commun. 2014, 5, 5634.

34 X. L. Ji, K. T. Lee, R. Holden, L. Zhang, J. J. Zhang, G. A. Botton, M. Couillard, L. F. Nazar, Nat. Chem. 2010, 2 (4), 286.

35 D. Volpe, E. Casado-Rivera, L. Alden, C. Lind, K. Hagerdon, C. Downie, C. Korzeniewski, F. J. DiSalvo, H. D. Abruña, J. Electrochem. Soc. 2004, 151, A971.

36 J. Liu, M. Jiao, L. Lu, H. M. Barkholtz, Y. Li, Y. Wang, L. Jiang, Z. Wu, D. J. Liu, L. Zhuang, C. Ma, J. Zeng, B. Zhang, D. Su, P. Song, W. Xing, W. Xu, Y. Wang, Z. Jiang, G. Sun, Nat. Commun. $2017,8,15938$

37 B. W. Zhang, Y. X. Jiang, J. Ren, X. M. Qu, G. L. Xu, S. G. Sun, Electrochim. Acta 2015, 162, 254.

38 A. Chen, P. Holt-Hindle, Chem. Rev. 2010, 110, 3767.

39 C. W. Xu, H. Wang, P. K. Shen, S. P. Jiang, Adv. Mater. 2007, $19,4256$.

40 S. Fu, C. Zhu, D. Du, Y. Lin, ACS Appl. Mater. Interfaces 2015 , 7, 13842.

41 Y. Qin, M. Luo, Y. Sun, C. Li, B. Huang, Y. Yang, Y. Li, L. Wang, S. Guo, ACS Catal. 2018, 8, 5581

42 Z. Y. Zhou, Q. Wang, J. L. Lin, N. Tian, S. G. Sun, Electrochim Acta 2010, 55, 7995

43 T. Sheng, W. F. Lin, C. Hardacre, P. Hu, Phys. Chem. Chem. Phys. 2014, 16, 13248. 